\title{
E-cigarette-induced pulmonary inflammation and dysregulated repair are mediated by $n A C h R$ a7 receptor: role of nAChR a7 in SARS-CoV-2 Covid-19 ACE2 receptor regulation
}

\author{
Qixin Wang ${ }^{1}$, Isaac K. Sundar ${ }^{1}$, Dongmei Li², Joseph H. Lucas' ${ }^{1}$, Thivanka Muthumalage',
} Samantha R. McDonough ${ }^{1}$ and Irfan Rahman ${ }^{1^{*}}$

\begin{abstract}
Electronic cigarette (e-cig) vaping is increasing rapidly in the United States, as e-cigs are considered less harmful than combustible cigarettes. However, limited research has been conducted to understand the possible mechanisms that mediate toxicity and pulmonary health effects of e-cigs. We hypothesized that sub-chronic e-cig exposure induces inflammatory response and dysregulated repair/extracellular matrix (ECM) remodeling, which occur through the a7 nicotinic acetylcholine receptor (nAChRa7). Adult wild-type (WT), nAChRa7 knockout (KO), and lung epithelial cell-specific $\mathrm{KO}$ (nAChRa7 CreCC10) mice were exposed to e-cig aerosol containing propylene glycol (PG) with or without nicotine. Bronchoalveolar lavage fluids (BALF) and lung tissues were collected to determine e-cig induced inflammatory response and ECM remodeling, respectively. Sub-chronic e-cig exposure with nicotine increased inflammatory cellular influx of macrophages and T-lymphocytes including increased proinflammatory cytokines in BALF and increased SARS-Cov-2 Covid-19 ACE2 receptor, whereas nAChRa7 KO mice show reduced inflammatory responses associated with decreased ACE2 receptor. Interestingly, matrix metalloproteinases (MMPs), such as MMP2, MMP8 and MMP9, were altered both at the protein and mRNA transcript levels in female and male KO mice, but WT mice exposed to PG alone showed a sex-dependent phenotype. Moreover, MMP12 was increased significantly in male mice exposed to PG with or without nicotine in a nAChRa7-dependent manner. Additionally, sub-chronic e-cig exposure with or without nicotine altered the abundance of ECM proteins, such as collagen and fibronectin, significantly in a sex-dependent manner, but without the direct role of nAChRa7 gene. Overall, sub-chronic e-cig exposure with or without nicotine affected lung inflammation and repair responses/ECM remodeling, which were mediated by $\mathrm{nAChRa7}$ in a sex-dependent manner.
\end{abstract}

Keywords: E-cig exposure, nAChRa7, Inflammation, Dysregulated repair, Extracellular matrix

\footnotetext{
* Correspondence: irfan_rahman@urmc.rochester.edu

'Department of Environmental Medicine, University of Rochester Medical

Center, Box 850, 601 Elmwood Avenue, Rochester, NY 14642, USA

Full list of author information is available at the end of the article
}

(c) The Author(s). 2020 Open Access This article is licensed under a Creative Commons Attribution 4.0 International License, which permits use, sharing, adaptation, distribution and reproduction in any medium or format, as long as you give appropriate credit to the original author(s) and the source, provide a link to the Creative Commons licence, and indicate if changes were made. The images or other third party material in this article are included in the article's Creative Commons licence, unless indicated otherwise in a credit line to the material. If material is not included in the article's Creative Commons licence and your intended use is not permitted by statutory regulation or exceeds the permitted use, you will need to obtain permission directly from the copyright holder. To view a copy of this licence, visit http://creativecommons.org/licenses/by/4.0/ The Creative Commons Public Domain Dedication waiver (http://creativecommons.org/publicdomain/zero/1.0/) applies to the data made available in this article, unless otherwise stated in a credit line to the data. 


\section{Introduction}

E-cigarettes (e-cigs) are often considered as a safer alternative to combustible cigarettes, as well as a method for quitting traditional cigarette smoking $[1,2]$. The e-cig delivery system is based on tanks or cartridges that are loaded with e-cig liquid (e-liquid), which is then aerosolized, with inhalation delivering the aerosol to the lungs. Usually, e-liquids are composed of propylene glycol (PG) and/or vegetable glycerin (VG), with varying concentrations of nicotine (up to $100 \mathrm{mg} / \mathrm{mL}$ ). Flavoring chemicals are added as additives in e-liquids and pods that enhance the taste and reduce throat hit, however they tend to attract the younger generation unexpectedly $[3,4]$. While PG and VG are considered safe in foodgrade products, adverse health effects have been reported from these substances when they serve as e-cig vehicles [5]. Previous studies have shown that the amount of nicotine delivered by e-cigs is much higher than the amount delivered via cigarette smoke $[6,7]$. We have shown that inflammation and extracellular matrix (ECM) remodeling/dysregulated repair are altered by acute exposure to e-cigs, with or without nicotine [8]. Considering that e-cig vaping is often a long-term habit, research on the chronic effects of e-cig aerosol exposure is essential to understand the mechanism resulting in augmented inflammatory responses and ECM remodeling, which are fundamental changes that occur during early stages of most chronic lung diseases, such as idiopathic pulmonary fibrosis (IPF) and chronic obstructive pulmonary disease (COPD) [9, 10].

In our previous studies, acute exposure to e-cig aerosol containing flavoring chemicals was shown to cause lung inflammation, oxidative stress, and dysregulated repair [8, 11]. Further, nicotine exposure could cause suppression of immune response resulting in augmented lung inflammation and injury following viral infection [12]. Nicotinic Acetylcholine Receptors (nAChRs) are largely responsible for activation of acetylcholine neurotransmitter signaling pathways in the central nervous system (CNS) [13, 14]. It has been postulated that angiotensin-converting enzyme 2(ACE2), a Covid-19 receptor, is regulated by nAChRs. The nAChRs are widely distributed in the CNS, so they can easily be activated by nicotine, initiating and reinforcing a rewarding feedback loop which might induce nicotine addiction $[15,16]$. Interestingly, lung nAChR activation could help inhibit the inflammation caused by lipopolysaccharides (LPSs) and the receptor knockouts (KOs) that promote inflammatory processes [17, 18]. However, as one of the nAChR-agonists, nicotine could initiate receptor-related pathways, and nicotine aerosol inhalation might also induce inflammation [11] and regulate ACE2 receptor via nAChR. Other chemicals may induce activation of nAChRs, and they may also trigger feedbackloops similar to flavoring chemicals [19-21]. However, there are limited studies that directly describe the role of dysregulated repair induced by e-cig vapors with or without nicotine in a nAChR $\alpha 7$-dependent manner.

A common vehicle used for nicotine delivery in e-cigs is PG and/or VG. PG $\left(\mathrm{C}_{3} \mathrm{H}_{8} \mathrm{O}_{2}\right)$ is a colorless and odorless organic solvent that is an FDA-approved, food-grade chemical generally recognized as safe (GRAS). This is one of the reasons why people originally thought to use PG as a nicotine carrier in e-liquids. Previous study has shown that PG aerosols produce different byproducts, some of which might lead to cancer [22]. Many e-cigs with or without nicotine are commercially available, but the understanding of respiratory health risks of e-cig inhalation are poorly investigated.

In this study, we hypothesized that e-cig aerosol induces lung inflammation and dysregulated repair/ECM remodeling in a $n A C h R \alpha 7$-dependent manner. Our results suggest that lung inflammatory responses and dysregulated repair/ECM remodeling induced by e-cig aerosol containing nicotine could potentially be related to the nAChR $\alpha 7$ signaling pathway. On the other hand, PG-induced lung dysregulated repair and inflammatory response occurs in a $\mathrm{nAChR} \alpha 7$-independent manner.

\section{Methods \\ Animals}

Adult C57BL/6 J (WT) mice and $\alpha 7$ nicotinic acetylcholine receptor knockout ( $\mathrm{AChR} \alpha 7 \mathrm{KO}$ ) mice were both purchased from Jackson Laboratory, weighing 25-35 g and aged 3-4 months old. The nAChR $\alpha 7$ CreCC10 mice (clara/club-cell-specific nAChR $\alpha 7$ deletion) were generated by crossing $n A C h R ~ \alpha 7$ floxed mice (nAChR $\alpha 7$ floxed mutant) from Jackson Laboratory (donated by Dr. Jerry Yakel, NIEHS/NIH) with mice having the Cre recombinase transgene controlled by the CC10 promoter (C57BL/6 J; from TJ Mariani, University of Rochester, Rochester, NY). Prior to e-cig exposure, mice were housed in the inhalation core facility at the University of Rochester for one week. All experiments performed in this study were in compliance with the standards set by the United States Animal Welfare Act. The Animal Research Committee (UCAR) approved the animal protocol at the University of Rochester Medical Center, Rochester, NY.

\section{Blood gas and exercise ability measurement}

Blood gas, including $\mathrm{pH}$, pressure of $\mathrm{CO}_{2}$ and $\mathrm{O}_{2}$, concentration of $\mathrm{HCO}_{3}, \mathrm{TCO}_{2}$, glucose $(\mathrm{Glu})$ and hemoglobin $(\mathrm{Hb})$, percentage of $\mathrm{O}_{2}$ and hematocrit $(\mathrm{Hct})$ were analyzed by i-STAT system (i-STAT CG8+ cartridge, Cat\# 03P8825; Vet scan i-STAT 1 analyzer; Abaxis Global Diagnostics), as described previously [23]. Exercise capacity measurement was done using a motorized animal treadmill (Columbus Instruments) as described previously [24]. Running distance (meters) and running time (minutes) were recorded to 
present exercise tolerance. Mice stayed on the treadmill for $5 \mathrm{~min}$ before start of measurement. The treadmill began at $8.5 \mathrm{~m} / \mathrm{min}$ with $0^{\circ}$ incline for $9 \mathrm{~min}$. Then, the speed was increased to $10 \mathrm{~m} / \mathrm{min}$ with $5^{\circ}$ incline for $3 \mathrm{~min}$. After that, the speed was increased to $2.5 \mathrm{~m} / \mathrm{min}$ every $3 \mathrm{~min}$, and incline was increased to $5^{\circ}$ every $9 \mathrm{~min}$ until the mouse became exhausted, judged by observation of failure of running and continuous contact with the electric grid. Following this exercise, blood was collected by submandibular venipuncture for blood gas and cotinine measurement.

\section{E-cig device and e-liquid}

The e-cig device used in this study was purchased from the Joytech VTC mini (SciReq, Montreal, Canada). The atomizer/coil $(0.15 \Omega)$ used for aerosolization of e-liquid was purchased from Kanger technology (Shenzhen, China). All other components of the e-cig exposure chamber were purchased from SCIREQ, and all the components were cleaned after exposure every day. The atomizer/coil was replaced on a weekly basis to avoid overheating and generation of carbon monoxide. The eliquids used in this study that contain PG alone and PG with nicotine $(25 \mathrm{mg} / \mathrm{mL})$, were purchased from xtremevaping.com.

\section{E-cig exposure}

The e-cig exposure performed here has been described in our previous studies [25]. Briefly, the in vivo e-cig exposure was setup inside a fume hood and based on the SCIREQ InExpose e-cig extension smoking system. The e-cig exposure puffing profile used was based on realistic topographical data from e-cig users, with $3.3 \mathrm{~s} /$ puff, 2 puffs/min and a $70 \mathrm{~mL}$ puff volume [26]. The aerosolization of e-liquid was performed by using a 3rd generation e-cig device (Joytech eVIC VTCmini), which was controlled by the SCIREQ flexiware software (V8.0). The whole-body exposure was done for a total of $2 \mathrm{~h} /$ day, 5 days/week, for 30 days. During e-cig exposures, temperature, humidity, oxygen and carbon dioxide percentages were monitored along with carbon monoxide levels in the chamber. The e-cig aerosol generated was passed through the condensing chamber and pumped into the mixing chamber with a flowrate of $1.0 \mathrm{~L} / \mathrm{min}$. The vapor was diluted with air in the mixing chamber and then delivered into the whole-body exposure chamber where mice were separated by dividers. Simultaneously, the e-cig aerosol in the exposure chamber was exhausted by another pump with a flowrate of $2.0 \mathrm{~L} /$ min. Both the pumps were calibrated and adjusted each time before exposure. Pumps were cleaned at the end of each exposure to minimize the effects of nicotine residues. Mice were divided into air (control), PG, and PG with nicotine groups, each with an equal number of males and females, for both the WT and nAChR $\alpha 7 \mathrm{KO}$ conditions. Air group mice stayed in the inhalation facility in a similar environment during the 30 day exposure. Serum cotinine levels measured by ELISA (Calbiotech) were $\sim 500 \mathrm{ng} / \mathrm{mL}$ for the PG with nicotine group, and $20 \mathrm{ng} / \mathrm{mL}$ for the PG only group, due to nicotine residue in the pumps and exposure chambers which was difficult to fully clean (Additional File 1: Figure S1). As expected, the air group showed no cotinine.

\section{Bronchoalveolar lavage fluid (BALF)}

Mice were euthanized with Ketamine/Xylazine $24 \mathrm{~h}$ after the final exposure. Their tracheas were cannulated and their lungs were lavaged three times with $0.6 \mathrm{~mL}$ saline with $1 \%$ FBS $(1.8 \mathrm{~mL}$ total). The recovered fluids were collected and spun down at $1000 \mathrm{x}$ g for $10 \mathrm{~min}$ at $4{ }^{\circ} \mathrm{C}$ for harvesting of BALF cells. The supernatant was stored at $-80{ }^{\circ} \mathrm{C}$ for future analysis. The BALF cells were resuspended in $1.0 \mathrm{~mL}$ saline with $1 \%$ FBS and stained with acridine orange propidium iodide $(\mathrm{AO} / \mathrm{PI})$. Total cell counts per $\mathrm{mL}$ were measured from $\mathrm{AO} / \mathrm{PI}$ stained cells via cellometer.

\section{Inflammatory cell count}

The resuspended BALF cells were used for immuneinflammatory cell counts with cell-type-specific labelled monoclonal antibodies. Total $1.0 \times 10^{5}$ BALF cells were used for antibody labeling. Before antibody staining, all cells were blocked with purified anti-mouse CD16/32 (Cat\# 50-163-432, Fisher Scientific) to prevent nonspecific binding, and washed with PBS once. The cells were stained with F4/80 PE-conjugated antibody for macrophages (Cat\# 123109, BioLegend), LY6B.2 Alexa fluor488-conjugated antibody for neutrophils (Cat\# NBP213077AF488, Novus Biologicals), PE-Cyanine7 antibody for CD4a ${ }^{+}$T-lymphocytes (Cat\# 25-0041-82, Fisher Scientific), and APC conjugated Monoclonal Antibody for CD8a ${ }^{+}$T-Lymphocytes (Cat\# 17-0081-82, Fisher Scientific). The absolute cell numbers of macrophages, neutrophils, and $\mathrm{CD} 4 \mathrm{a}^{+} / \mathrm{CD} 8 \mathrm{a}^{+} \mathrm{T}$-lymphocytes were determined by multiplying the percentage of cells by the total cell counts. Flow cytometry was performed using the Guava ${ }^{\circ}$ easyCyte ${ }^{\mathrm{m}}$ flow cytometer (Millipore Sigma) and analyzed using Guava ${ }^{\circ}$ InCyte ${ }^{\text {tw }}$ software.

\section{Measurement of pro-inflammatory cytokines by Luminex in BALF}

To measure the pro-inflammatory cytokines present in BALF, a Bio-Plex Pro mouse cytokine 23-plex immunoassay kit (Cat\#: M60009RDPD, BioRad) was used, according to the manufacturer's instructions. Briefly, the diluted magnetic beads were placed into the assay plate and rinsed with wash buffer. The BALF samples and standards were then added into the wells, and shaken at $850 \mathrm{rpm}$ at room temperature for $30 \mathrm{~min}$. After sample 
incubation, the plates were washed with wash buffer 3 times, then the detection antibody was added and the plates incubated for $30 \mathrm{~min}$ at room temperature, shaking at $850 \mathrm{rpm}$. Next, plates were washed with wash buffer 3 times, and SA-PE was added for $10 \mathrm{~min}$ at room temperature, shaking at $850 \mathrm{rpm}$. After this step, the plates were washed 3 times with wash buffer, and the beads were resuspended in assay buffer for reading. Results are determined via the Luminex flexmap 3d (Luminex Corp).

\section{Protein isolation}

Lung tissues harvested from the animals during sacrifice were stored at $-80^{\circ} \mathrm{C}$ for future analysis. Frozen lungs were homogenized mechanically in RIPA buffer with protease inhibitor (Cat\#: 78440, ThermoFisher Scientific). After homogenization, lysates were kept on ice for $45 \mathrm{~min}$, followed by centrifugation at $15,000 \mathrm{x} \mathrm{g}$ for 30 min at $4{ }^{\circ} \mathrm{C}$. The supernatant was collected and protein concentration was quantified using the Pierce BCA Protein Assay Kit (Cat\#: 23227, ThermoFisher Scientific), based on the manufacturer's protocol.

\section{Western blot}

The protein samples from lung homogenates were running through SDS-polyacrylamide electrophoresis gels (SDS-PAGE: 10\%) with $20 \mu \mathrm{g}$ of protein in each lane. After electrophoresis, the gel was transferred onto a nitrocellulose membrane (Cat\# 1620112, BioRad). The membrane was washed with tris-buffered saline containing 0.1\% Tween 20 (TBS-T) for $15 \mathrm{~min}$, then blocked with 5\% nonfat dry milk for $1 \mathrm{~h}$ at room temperature. Then, the membranes were probed with primary antibodies $16 \mathrm{~h}$ at $4{ }^{\circ} \mathrm{C}$ : anti-MMP2 (1:1000, ab92536, Abcam); anti-MMP9 (1: 1000, ab38898, Abcam); anti-MMP8 (1:1000, ab81286, Abcam); anti-MMP12 (1:1000, NBP2-67344, Novus Biologicals); anti-Collagen $1 \alpha 1$ (1:1000, NBP1-30054, Novus Biologicals); anti-Collagen 1 $\alpha 2$ (1:500, NBP1-57987, Novus Biologicals); anti-fibronectin (1:2000, ab45688, Abcam); and anti-PAI-1 (1:1000, ab182973, Abcam),antiACE2 (1:1000, ab15348, Abcam), and the appropriate secondary antibody (Goat-Anti-Rabbit, 1:10000, Cat\# 1706515, BioRad) for $1 \mathrm{~h}$ at room temperature. After each antibody incubation, membrane was washed 4 times in TBS-T at room temperature, $15 \mathrm{~min}$ per wash. The luminescence signals were developed using chemiluminescence substrate (Perkin Elmer, Waltham, MA). The membrane exposure and band intensities were detected via the Bio-Rad ChemiDoc MP imaging system (Bio-Rad Laboratories, Hercules, CA, USA). Protein quantification was done by densitometry analysis, and $\beta$-actin (1:2500, ab20272, Abcam) was used as housekeeping control.

\section{RNA isolation and Nanostring quantification}

Frozen lung tissues from $-80^{\circ} \mathrm{C}$ were used for RNA isolation. Lung tissue $(\sim 100 \mathrm{mg}$ per sample was homogenized in Trizol for 20s. The RNA was isolated using the Direct-zol $^{\text {mi }}$ RNA Miniprep Plus assay kit (Cat\# R2073, Zymo Research). Isolated RNA was quantified and checked for quality by spectrophotometer (ND-1000, NanoDrop Technologies, Wilmington, DE, USA). RNA samples were aliquoted and sent out to Nanostring facility for analysis of genes using nCounter Mouse Myeloid Innate Immunity v2 Panel (NanoString Technologies, Inc. Cat\# XT-CSO-MMII2-12).

\section{Statistical analysis}

The statistical analysis was done by either one-way ANOVA or student's t-test, followed by Tukey's multiple comparisons in GraphPad Prism software (Version 8.0, La Jolla, CA). Results were presented as the mean \pm SEM. $P<0.05$ was considered statistically significant.

\section{Results}

Sub-chronic e-cig exposure altered exercise capacity and blood-gas saturation

After 30 day e-cig exposure, WT (floxed) mice showed no difference in exercise capacity among the groups (Additional File 1: Figure S2). However, nAChR $\alpha 7$ deficient (KO) mice showed less capacity to run when exposed to PG with nicotine compared to air control and PG alone groups. Similar results were observed in nAChR $\alpha 7$ lung epithelial cell-specific conditional KO mice exposed to PG with nicotine, which showed reduced exercise capacity compared to air control and PG alone groups. E-cig aerosol with nicotine exposure in $\mathrm{nAChR} \alpha 7 \mathrm{KO}$ mice show lowered exercise capacity indicating the possible role of $n A C h R \alpha 7$ in the lung epithelium. Blood $\mathrm{pH}, \mathrm{O}_{2}$ pressure, and concentrations of $\mathrm{HCO}_{3}$ and $\mathrm{CO}_{2}$ were shown to be dysregulated when WT mice were exposed to PG with nicotine compared to PG alone, while no difference was observed between WT and nAChR $\alpha 7 \mathrm{KO}$ mice exposed to PG with or without nicotine (Additional File 2: Table S1).

\section{Sub-chronic e-cig exposure induces inflammatory cellular influx in the mouse lung}

The total cell counts were increased in WT mice exposed to PG with or without nicotine relative to respective air group, and total cell counts in WT mice exposed to PG with nicotine increased significantly compared to air and PG alone groups (Fig. 1a). The nAChR $\alpha 7 \mathrm{KO}$ mice showed no change in total cell counts when exposed to PG with nicotine (Fig. 1a). However, the total cell counts were increased but not significantly compared to respective control group (Fig. 1a). Macrophage counts followed a similar trend as observed in total cell 

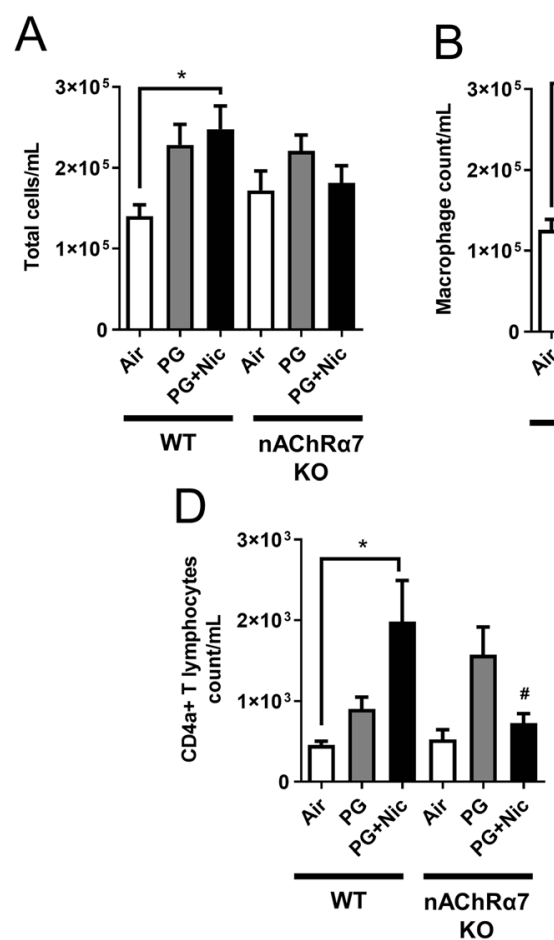
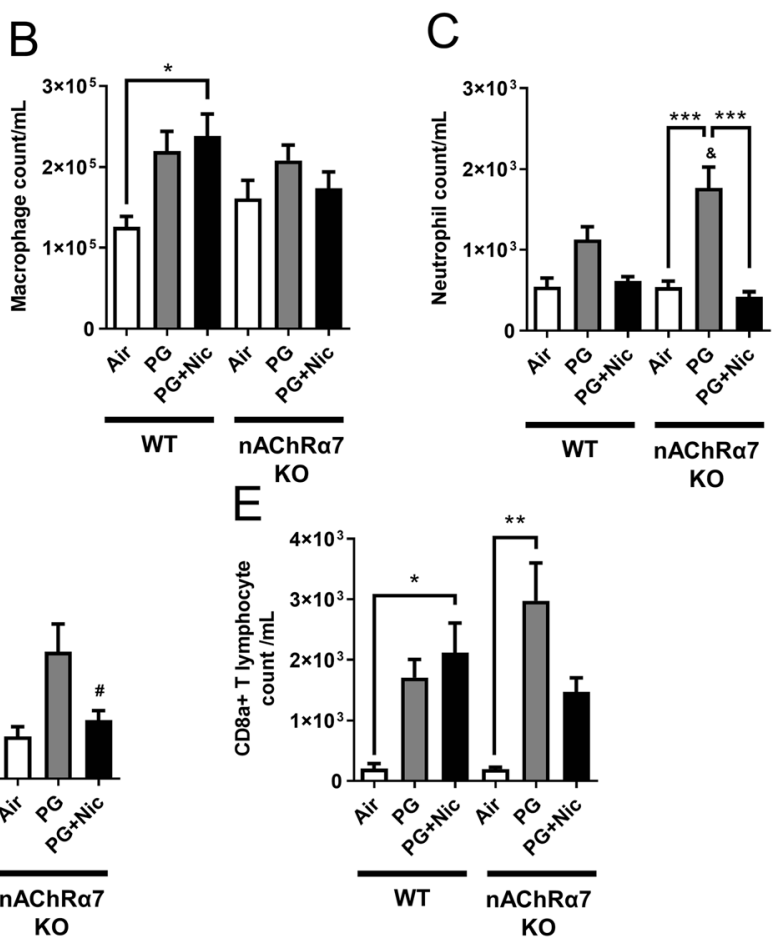

Fig. 1 Sub-chronic e-cig exposure augments inflammatory cell influx in BALF. Differential inflammatory cell counts were measured in BALF from mice exposed to air, PG or PG with nicotine ( $\mathrm{PG}+\mathrm{Nic}$ ) for 30 days ( $2 \mathrm{~h} /$ day). (a) Total inflammatory cell counts were analyzed by Cellometer using $\mathrm{AO} / \mathrm{PI}$ staining. Differential inflammatory cell counts were determined as percentages by flow cytometry. Absolute cell counts for (b) F4/80+

macrophages, (c) Ly6B.2+ neutrophils, (d) CD4a + T-lymphocytes, and (e) CD8a + T-lymphocytes were normalized to the total cell counts. Data are shown as mean \pm SEM ( $n=4-6 /$ group; equal number of male and female mice). ${ }^{*} P<0.05$, ${ }^{* *} P<0.01$ between groups; \& $P<0.05$, compared to PG exposed WT group; \# $P<0.05$, compared to PG + Nic exposed WT group

counts (Fig. 1b). WT and nAChRa7 KO mice exposed to PG with nicotine showed no change in neutrophil counts in BALF (Fig. 1c). Additionally, $\mathrm{CD}_{4} \mathrm{a}^{+}$and $\mathrm{CD} \mathrm{a}^{+} \mathrm{T}$-lymphocyte counts were significantly increased when WT mice were exposed to PG with nicotine, and loss of nAChR $\alpha 7$ prevents increase in T-lymphocytes (Fig. 1d-e). PG-exposed nAChR $\alpha 7 \mathrm{KO}$ mice showed higher levels of neutrophils and $\mathrm{CD} 4 \mathrm{a}^{+} / \mathrm{CD} 8 \mathrm{a}^{+} \mathrm{T}$ lymphocytes than PG-exposed WT mice (Fig. 1c-e).

\section{Sub-chronic e-cig exposure augments influx of pro- inflammatory cytokines in BALF}

We next determined the level of pro-inflammatory cytokines in BALF after sub-chronic e-cig exposure. Most of the pro-inflammatory cytokines in BALF were significantly increased in WT mice exposed to PG with nicotine compared to PG alone and air control (Fig. 2 and Additional File 2: Table S2). We have noticed that macrophage-mediated pro-inflammatory cytokines, IL$1 \alpha$, MCP-1, and GM-CSF were significantly increased in WT mice exposed to PG with nicotine, and $\mathrm{nAChR} \alpha 7$ KO blocks the release of these mediators (Fig. 2). Similarly, lymphocytes-related cytokines, IL-2, IL-9, IFN $\gamma$, and RANTES showed a nAChR $\alpha 7$-dependent reduction in cytokine levels (Fig. 2). Additionally, TNF $\alpha$, MIP-1 $\beta$, IL-1 $\beta$ and IL-5 were increased in PG with nicotine exposed WT mice, but not in nAChR $\alpha 7 \mathrm{KO}$ mice exposed to PG with nicotine. The remaining cytokines IL-3, IL-4, IL-10, IL-12p40, IL-17A, G-CSF, and MIP-1 $\alpha$ were not affected among any of the exposure groups in WT and $\mathrm{nAChR} \alpha \mathrm{KO}$ mice compared to respective air control (Additional File 2: Table S2).

Sub-chronic e-cig exposure alters mRNA transcript levels of inflammation and dysregulated repair response genes in WT and $\mathrm{nAChRa7} \mathrm{KO}$ mice

To further determine whether sub-chronic e-cig exposure-mediated inflammatory responses and dysregulated repair/ECM remodeling was caused by altered expression of myeloid innate immune response target genes ( $\sim 734$ genes), we performed gene expression analysis using nCounter Mouse Myeloid Innate Immunity Panel (Nanostring Technologies, Inc.). The datasets were analyzed by Nanostring nSolver and R programming (Additional file 3: Table S3). The distribution of normalized transcript levels among different experimental groups was presented as boxplot (Fig. 3a). The pairwise comparison between PG alone exposed WT and 


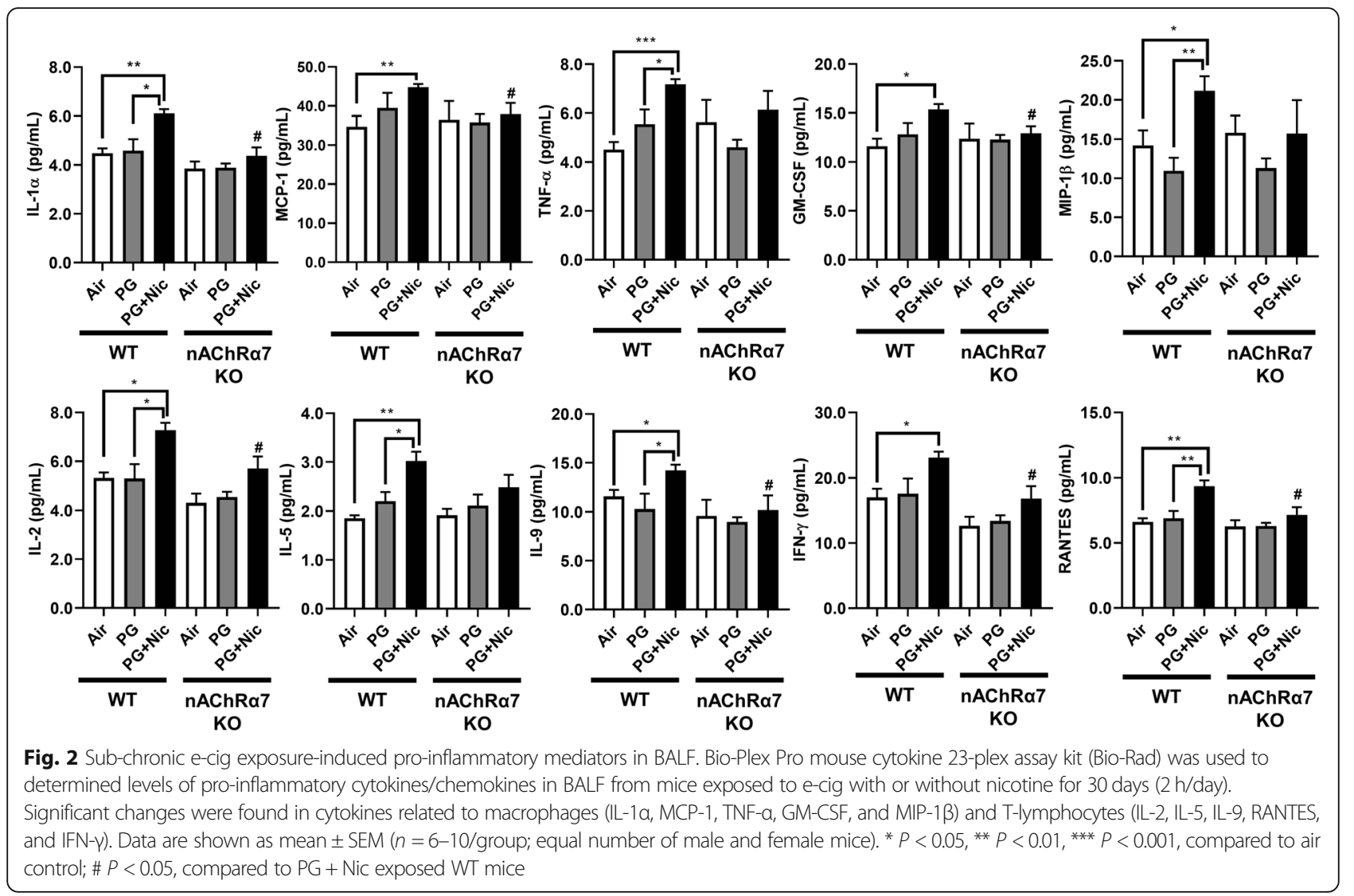

nAChR $\alpha 7 \mathrm{KO}$ mice revealed 21 genes that were differentially expressed compared to respective air control (Fig. 3b). Additionally, pairwise comparison analysis among PG with nicotine exposed WT and nAChR $\alpha 7$ KO mice revealed 89 genes differentially expressed when compared to respective air control (Fig. 3b). Furthermore, pairwise comparison between PG with nicotine and PG alone groups in WT and nAChR $\alpha 7$ $\mathrm{KO}$ mice revealed 57 differentially expressed genes (Fig. 3b).

WT mice showed significantly higher RNA counts indicative of increased mRNA transcript levels for multiple targets in PG with or without nicotine exposed groups, compared to air control (Additional File 1: Figure S3). When we compared WT mice exposed to PG alone, air control or PG with nicotine we found altered gene expression of inflammatory and ECM remodeling targets such as matrix metalloproteases (MMP9 and MMP8), S100A8, and collagens (COL17A1 and COL14A1) (Additional File 1: Figure S3A). When WT mice exposed to PG with nicotine were compared with air control, we found a significant difference in transcript levels of inflammatory targets such as ARG1 and LPL (Additional File 1: Figure S3A). PG with nicotine exposure caused significant alterations in the expression of several target genes such as SMAD7, KLF4, CDH1, COL4A2, ICAM1,
LDLR, IL1B, TLR5, NFKBIA, and CXCL2 among WT and nAChR $\alpha 7 \mathrm{KO}$ mice that belong to the broad categories inflammation and dysregulated repaired/ECM remodeling (Additional File 1: Figure S3B). Based on the above-mentioned gene expression analysis by Nanostring, we chose specific target genes for further analysis (Fig. 4).

Based on the Nanostring nCounter analysis, transcript levels of target genes that showed significant differences between WT and nAChR $\alpha 7$ KO mice following PG with nicotine exposure were selectively represented in Fig. 4a. The gene expression levels of SKIL (Ski-like protein) and LDLR (Low-density lipoprotein receptor) were significantly decreased in WT mice exposed to PG with nicotine, but not $\mathrm{nAChR} \alpha 7 \mathrm{KO}$ mice. However, gene expression levels of CCL9 (Chemokine ligand 9), KLF4 (Kruppel-like factor 4), DUSP1 (Dual Specificity Phosphatase 1), BTLA (B and T Lymphocyte Associated), and SMAD7 (SMAD Family Member 7) were significantly increased only in nAChR $\alpha 7 \mathrm{KO}$ mice exposed to PG with nicotine compared to WT mice (Fig. 4a). Finally, NECTIN1 gene expression in WT and nAChR $\alpha 7$ KO mice showed a decreased trend, but only WT mice exposed to PG with nicotine showed a significant reduction in the expression of NECTIN1 transcript compared to air controls (Fig. 4a). 


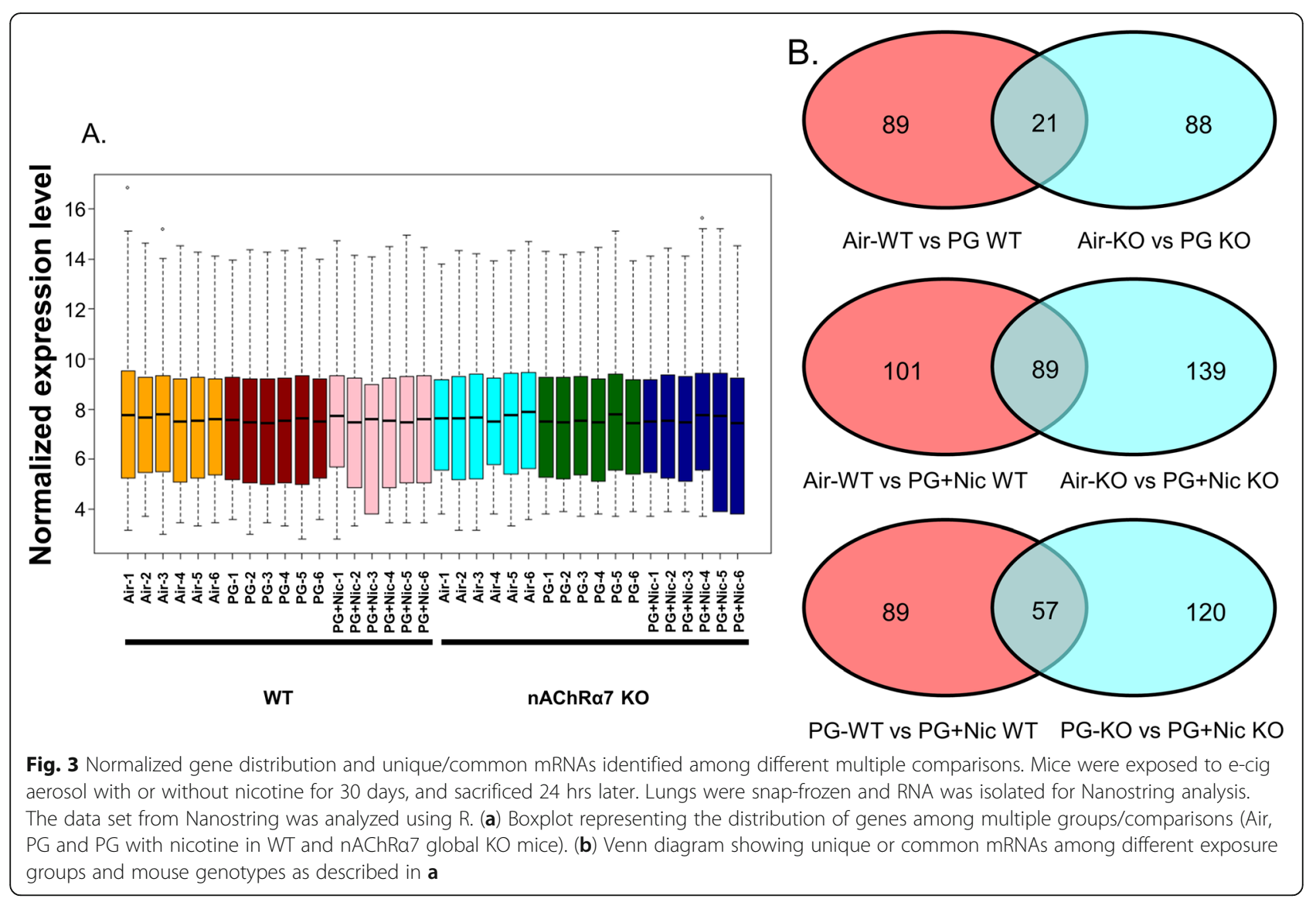

\section{Sub-chronic e-cig exposure with nicotine in $\mathrm{nAChR} a 7$ deficient mice prevents dysregulation of p50/p105}

In order to determine the role of target molecules that contribute to e-cig exposure induced inflammatory response at the protein level, we measured the protein abundance of a NF- $\mathrm{BB}$ subunit (nuclear factor kappalight-chain-enhancer; p50/p105). We have observed that the protein levels of both p50 and p105 were upregulated in WT female mice exposed to PG with nicotine, while $\mathrm{nAChR} \alpha \mathrm{KO}$ showed attenuation of p50 and p105 expression in the lungs (Fig. 5a). However, there was no significant difference in male mice exposed to PG with or without nicotine compared to air control in either WT or nAChR $\alpha$ KO mice (Fig. 5a). WT or nAChR $\alpha 7$ KO female mice exposed to PG alone showed similar upregulation of $\mathrm{p} 105$, indicating that PG alone could induce pro-inflammatory responses in a nAChR $\alpha 7$-independent manner (Fig. 5a).

Sub-chronic e-cig with nicotine exposure induced upregulation of angiotensin-converting enzyme 2 (ACE2) in mouse lung

Recently, it has been shown that ACE2 (Covid-19 receptor) is a key point in migration of fibroblasts to injured locations in lungs, and ACE2 is involved in lung ECM remodeling. We determined the protein abundance of ACE2 (Fig. 5b). We have noticed that PG with nicotine has increased the protein abundance, whereas nAChR $\alpha 7$ deletion attenuated this dysregulation in females. While in males, there was no difference between PG with nicotine exposure and air control, PG exposure decreased the ACE2 protein level, and nAChR $\alpha 7$ knockdown lowered the baseline abundance of ACE2 in lungs.

\section{Sub-chronic e-cig exposure with or without nicotine induces dysregulated repair/ECM remodeling in a $\mathrm{nAChR}$ a7-independent manner}

In our previous study, we have identified that acute e-cig exposure causes dysregulated repair/ECM remodeling in mouse lungs [8]. In this study, we were interested to investigate the role of dysregulated repair/ECM remodeling in sub-chronic e-cig exposed WT and $\mathrm{nAChR} \alpha 7 \mathrm{KO}$ mice. We were specifically interested in selected MMPs and ECM remodeling markers to determine their effects following sub-chronic e-cig exposure both at the gene expression (Fig. 4b) and protein abundance levels (Figs. 6 and 7).

PG exposed WT and nAChR $\alpha 7$ KO mice showed decreased expression of MMP8 and MMP9 compared 


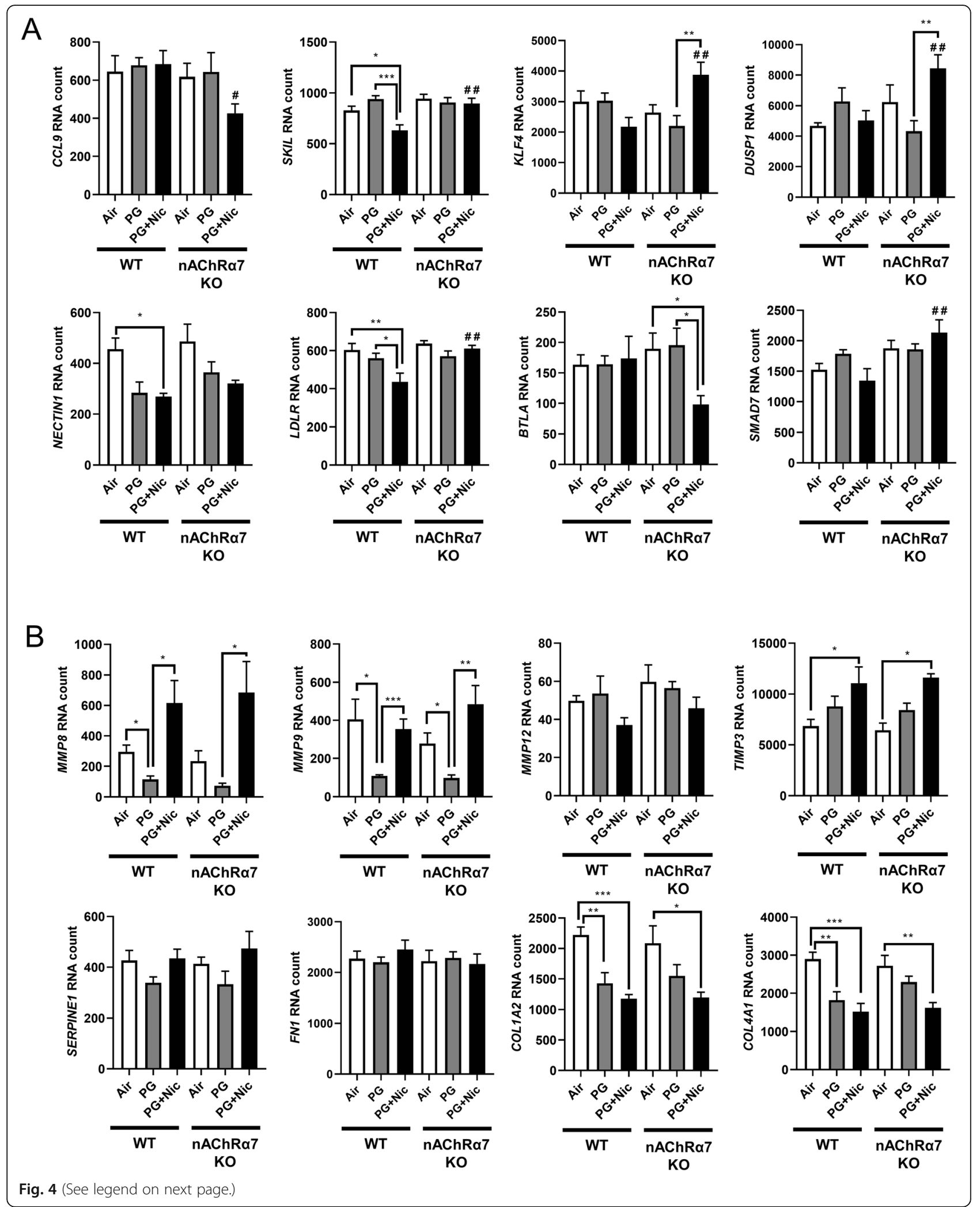


(See figure on previous page.)

Fig. 4 Sub-chronic e-cig exposure affects mRNA expression of myeloid and innate immune response target genes analyzed by Nanostring analysis. Mice were exposed to e-cig aerosol with or without nicotine for 30 days ( 2 hrs/day), and sacrificed 24 hrs after final exposure. RNA was isolated from lungs and screened via nCounter Mouse Myeloid Innate Immunity Panel using Nanostring analysis. Targets were selected based on significant differences, especially (a). between) PG+Nic exposed WT and nAChRa7 KO mice, or (b) ECM remodeling focused. RNA counts were normalized to multiple housekeeping genes and quantified using nSolver. Data are shown as mean \pm SEM ( $n=6 /$ group; equal number of male and female mice). ${ }^{*} P<0.05,{ }^{* *} P<0.01,{ }^{* * *} P<0.001$ between groups; \# $P<0.05$, \# \# $P<0.01$ compared with PG+Nic exposed WT group

to air control and PG with nicotine groups (Fig. 4b). WT and nAChR $\alpha 7$ KO mice exposed to PG with nicotine showed significant increases in TIMP3, which is an inhibitor of MMPs (Fig. 4b). ECM target genes fibronectin (FN1) and Plasminogen activator inhibitor-1 (PAI-1, gene code: SERPINE1) were unaffected, while genes that modulate collagen expression (COL1A2 and COL4A1) significantly decreased in PG with or without nicotine exposed WT and nAChR $\alpha 7 \mathrm{KO}$ mice.

Based on the gene expression changes in dysregulated repair markers, we measured the protein abundances of the same in e-cig exposed WT and $n A C h R \alpha 7 \mathrm{KO}$ mice. Results from immunoblot analysis correlated with gene expression of MMP9 and MMP8 in both female and male mice (Fig. 6a-b). Decreased MMP8 and MMP9 were also observed in PG-exposed WT and nAChR $\alpha 7$ KO mice compared to PG with nicotine and air control (Fig. 6a-b). MMP2 protein abundance was increased in WT male and female mice exposed to PG alone, compared to air control and PG with nicotine-exposed mice. Moreover, nAChR $\alpha 7$ KO female mice show increased MMP2 protein abundance at baseline, while no change was observed in male mice (Fig. 6a-b). The protein levels of MMP9, MMP2, and MMP12 were increased in WT male mice exposed to PG with nicotine, while $\mathrm{nAChR} \alpha 7$ $\mathrm{KO}$ inhibits protein abundance of MMPs (Fig. 6b). MMP8 protein levels were comparable in female and male mice and $\mathrm{nAChR} \alpha 7 \mathrm{KO}$ showed decreased protein abundance of MMP8 at baseline (Fig. 6a-b).

ECM proteins/regulators such as collagens, fibronectin, and PAI-1, were measured in WT and $\mathrm{nAChR} \alpha 7 \mathrm{KO}$ mouse lungs (Fig. 7). The protein abundance of PAI-1 showed no difference among air, PG alone and PG with nicotine exposed WT and $\mathrm{nAChR} \alpha \mathrm{KO}$ female mice (Fig. 7a). Whereas PAI-1 was increased in WT male mice exposed to PG with nicotine, but was reduced in nAChR $\alpha 7$ KO male mice (Fig. 7b). Furthermore, two different subunits of type 1 collagens (COL1A1 and COL1A2) were differentially expressed at the protein level among the experimental groups. WT and $\mathrm{nAChR} \alpha 7 \mathrm{KO}$ female and male mice showed increased expression of COL1A2 when exposed to PG alone (Fig. 7). However, COL1A1 protein abundance was reduced in WT male mice exposed to PG with or without nicotine, and $\mathrm{nAChR} \alpha 7$ deficiency further decreased the baseline of COL1A1 levels in male mice.
There is no change in the protein levels of COL1A1 among PG alone and PG with nicotine exposure in WT and $n A C h R \alpha 7$ KO mice. PG with or without nicotine exposure reduced the protein abundance of fibronectin in WT female and nAChR $\alpha 7 \mathrm{KO}$ mice compared to air control (Fig. 7a). However, a decreased fibronectin protein level was observed in the PG-exposed WT male mice, and there was no alteration in $\mathrm{nAChR} \alpha 7 \mathrm{KO}$ male mice among all the different exposure conditions (Fig. 7b).

\section{Sub-chronic e-cig exposure in lung epithelial cell-specific} $\mathrm{nAChR}$ a7 deletion protects against inflammation Considering the inflammatory responses seen in WT and $\mathrm{nAChR} \alpha 7 \mathrm{KO}$ mice, we exposed $\mathrm{nAChR} \alpha$ 7 lung epithelial cell-specific $\mathrm{KO}$ mice to e-cig aerosol with or without nicotine to determine the role of $n A C h R \alpha 7$ in the lung epithelium. Surprisingly, we did not see any significant changes in pro-inflammatory cytokines following PG with nicotine exposure in nAChR $\alpha 7$ epithelial cell-specific $\mathrm{KO}$ mice. However, IL-5, MCP-1, KC, Eotaxin, GM-CSF, and G-CSF levels were significantly increased in PG alone group when compared to air control, and these cytokines were inhibited in nAChR $\alpha 7$ epithelial cell-specific KO mice (Additional File 1: Figure S4A). The rest of the cytokines from BALF showed no changes among all exposure groups in $\mathrm{nAChR} \alpha 7$ epithelial cell-specific $\mathrm{KO}$ mice (Additional File 1: Figure S4B-C).

\section{Discussion}

The popularity of e-cig vaping has been rising recently in the United States, and hence health concerns about vaping have recently attracted public attention [27]. Our previous studies have shown that acute exposure to e-cigarettes could cause inflammatory responses, oxidative stress, and ECM remodeling $[8,11,28]$. Although in the past we have shown the health risks caused by acute e-cig exposures in mice $[8,11]$, sub-chronic or chronic effects of e-cig exposure-induced toxicity and respiratory health effects remain elusive. Based on our knowledge, no study has yet shown that long-term exposure of e-cig aerosol can result in persistent dysregulated repair/ECM remodeling and inflammatory responses implicating the role of the $\mathrm{nAChR} \alpha \mathrm{7}$ receptor in the lung.

Similar to our acute exposure results, e-cig aerosol with nicotine induced inflammatory cell counts in BALF compared to air control, especially in macrophages and 

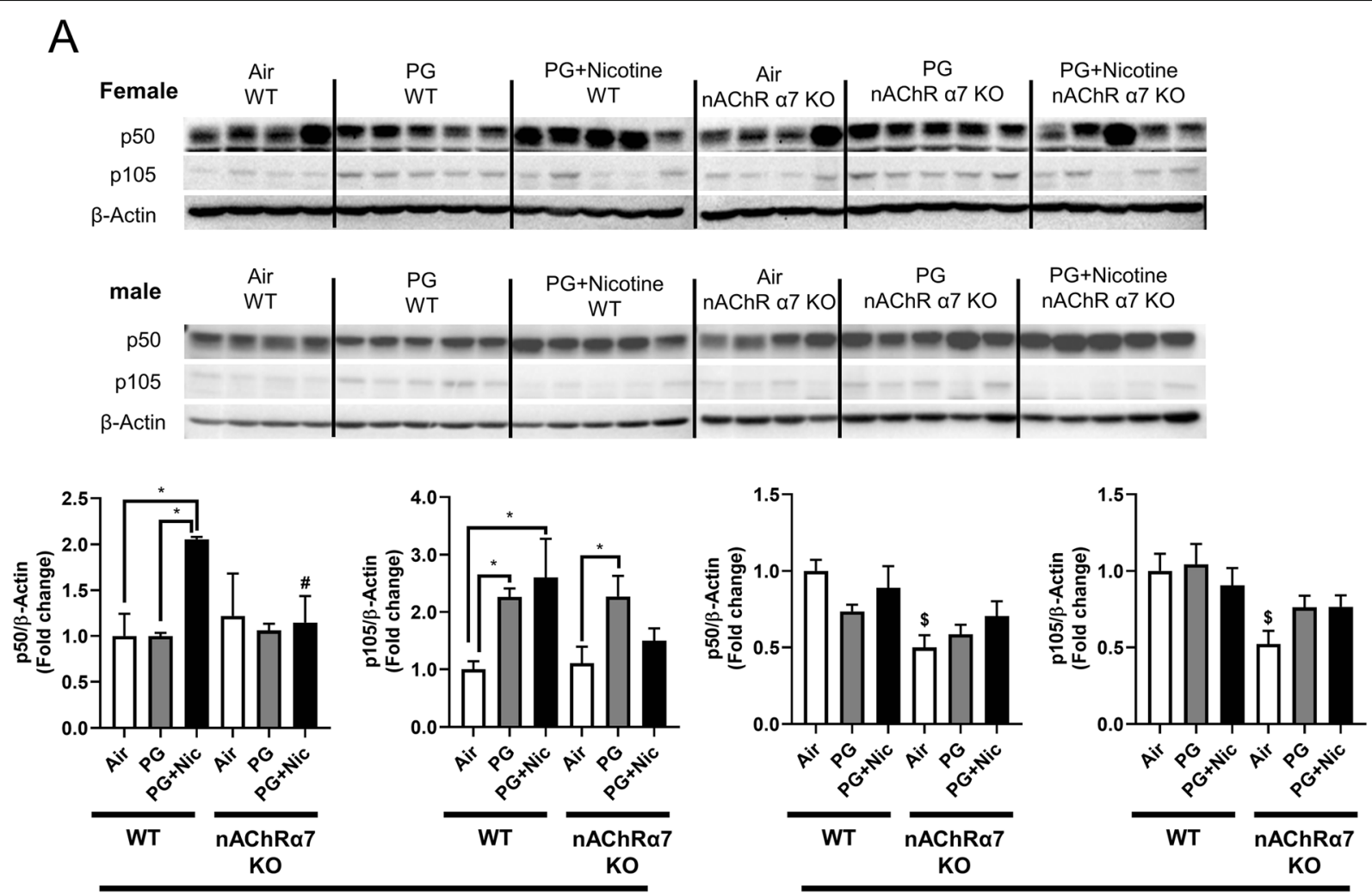

Female

Male

B

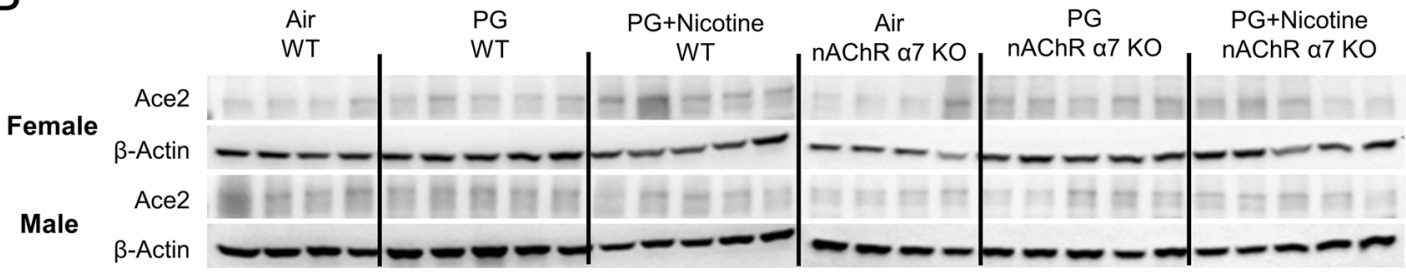

Female

Male
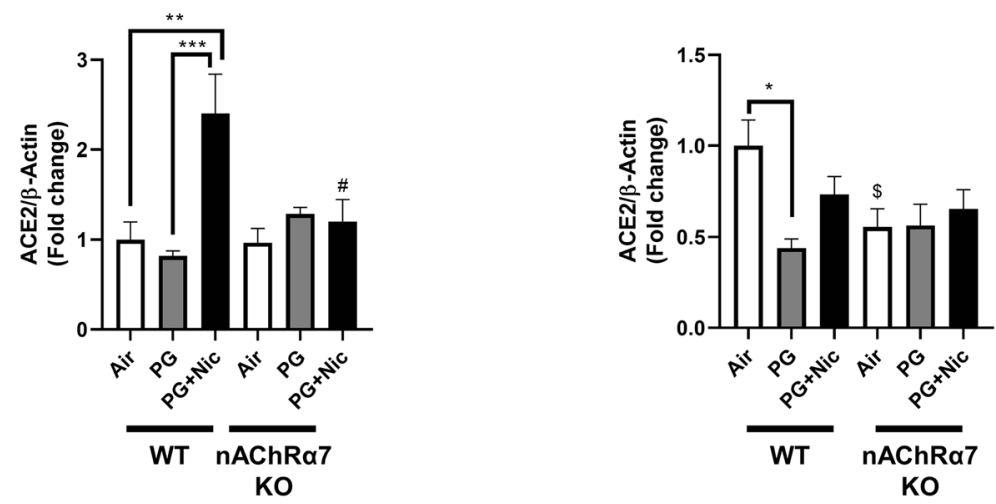

Fig. 5 (See legend on next page.) 
(See figure on previous page.)

Fig. 5 Sub-chronic e-cig exposure lead to dysregulateddifferentially affects the protein abundance of NF-kB subunits (p50/p105) and Angiotensinconverting enzyme 2 (ACE2) in mouse lungs with sex differences. The protein abundance of (a) p50/p105 and (b) Angiotensin-converting enzyme 2 (ACE2) were measured in whole lung homogenates via Western blot. Representative blot images for female and male mice are shown. Densitometry analysis of individual blots was performed for p50/p105 and ACE2 for both female and male, and $\beta$-actin was used as an endogenous control. Data are shown as mean \pm SEM. ( $n=4$-5/group). * $P<0.05$ significant compared between groups; $P<0.05$, compared with air exposed $W T$ group; \# $P<0.05$, compared with PG+Nic exposed WT group

$\mathrm{CD} 4 \mathrm{a}^{+} / \mathrm{CD} 8 \mathrm{a}^{+} \mathrm{T}$-lymphocytes. Previous report has demonstrated that two weeks of e-cig (with nicotine) exposure increased the number of macrophages but not neutrophils, which supports our findings [29]. Another study reported that acute exposure of e-cig aerosol increased total cell and macrophage counts; and even the vehicle exposure alone showed a trend towards increase in total cells and macrophages [30]. Based on our results, e-cig exposure with or without nicotine causes increased inflammatory cellular influx into the lungs (BALF). PG alone (vehicle) exposure was considered safe by e-cig users, but our data reveals that sub-chronic e-cig exposure with PG (without nicotine) induced lung inflammation. The genetic ablation of $n A C h R \alpha 7$ protects against e-cig exposure induced increase in macrophages and CD4 $\mathrm{a}^{+} / \mathrm{CD} 8 \mathrm{a}^{+} \mathrm{T}$-lymphocytes. Probably, e-cig exposure containing PG with nicotine causes lung inflammation/ remodeling response via the $\mathrm{nAChR} \alpha 7$ receptor mediated signaling pathway, and blocking the receptor could attenuate nicotine-dependent effects in the lungs. Prior reports show that activation of $\mathrm{nAChR}$ can also inhibit inflammation [31], and we have observed increased neutrophils and $\mathrm{CD} 4 \mathrm{a}^{+} / \mathrm{CD} 8 \mathrm{a}^{+} \mathrm{T}$-lymphocytes when exposed to PG alone in nAChR $\alpha 7 \mathrm{KO}$ mice. The nAChR deletion may promote inflammation independent of nicotine exposure in the lungs. The chemicals derived from e-cig aerosols containing PG, such as formaldehyde, acetaldehyde, and methylglyoxal, in nicotine-free aerosol [32] may result in increased inflammation. As reported previously, both e-cig with or without nicotine caused infiltration of inflammatory cells and pro-inflammatory mediators that are key players for causing lung inflammatory response $[8,11,30]$. As an agonist of $n A C h R \alpha 7$, nicotine might be both pro-inflammatory and anti-inflammatory roles, and further research is needed to study the relationship between nicotine and nicotinic receptors in the context of sub-chronic e-cig exposure.

Apart from the inflammatory cells, some proinflammatory mediators in BALF were significantly increased following e-cig exposure with nicotine. Specific macrophage-mediated pro-inflammatory cytokines such as IL-1 $\alpha$, MCP-1, and GM-CSF, were increased in BALF after PG with nicotine exposure in a nAChR $\alpha 7$-dependent manner. However, a few other macrophage-driven cytokines, IL-1 $\beta$, TNF- $\alpha$, and MIP-1 $\beta$, did not show nAChR $\alpha 7$ dependency. Our results paralleled reports that e-cig aerosol containing nicotine induced cytotoxicity in alveolar macrophage and significant release of inflammatory mediators (TNF- $\alpha$, CXCL-8, MCP-1, and IL-6) [33]. Additional studies have shown specific T-lymphocyte-related cytokines/ chemokines (IL-2, IL-9, IFN- $\gamma$, and RANTES) and their role in inflammatory signaling [34-37], and our results indicated that these altered cytokine responses were nAChRdependent in e-cig exposed mouse lungs. Mice exposed to PG with nicotine showed increased IL-5 release in a $\mathrm{nAChR}$ independent manner. Another report shows increased IL-4, IL-5, and IL-13 levels following e-cig containing nicotine when challenged to ovalbumin treated mice resulting in exacerbation of allergic airway inflammation [38]. The increased IFN- $\gamma$ production has been related to cytotoxicity and infiltration of CD8 $\mathrm{a}^{+} \mathrm{T}$-cells $[39,40]$. This altered pro-inflammatory cytokine response and cellular influx in the lung are inter-connected to each other partly due to $\mathrm{nAChR} \alpha 7$ mediated signaling. It is possible that nAChR $\alpha 7$ deletion could attenuate the inflammatory responses induced by e-cig aerosol contained nicotine in the lungs. However, PG-induced increase in $\mathrm{CD}_{4} \mathrm{a}^{+} / \mathrm{CD} 8 \mathrm{a}^{+} \mathrm{T}$ lymphocytes does not corroborate with the cytokine levels. Future studies will address immune cell-type specific role in pulmonary toxicity of e-cig with and without nicotine during long-term exposure in mice.

We measured the mRNA expression using the mouse myeloid innate immunity panel from Nanostring technology to screen the potentially affected target genes. Our results showed altered expression of SKIL and LDLR in PG with nicotine-exposed WT mice, but the same genes remain unaffected in $\mathrm{nAChR} \alpha \mathrm{KO}$ exposed groups. These target genes have been shown to play vital roles in TGF $\beta /$ SMAD canonical signaling and TGF $\beta$-induced epithelialmesenchymal transition (EMT) may be inhibited by SKIL binding to SMAD $[41,42]$ In this study, we found increased protein abundance of PAI-1 in WT mice exposed to PG with nicotine, but PAI-1 was further reduced in nAChR $\alpha 7$ KO mice. Our results suggest that e-cig exposure of PG with nicotine may affect SKIL-TGF $\beta$-PAI-1 axis in the lung possibly through $\mathrm{nAChR} \alpha 7$ activation. The other important target significantly altered by PG with nicotine is LDLR gene. Overexpression of LDLR is capable of promoting macrophage differentiation and exaggerated inflammatory response, and silencing LDLR results in reduced inflammatory responses in THP-1 cells [43]. In our study, LDLR was reduced in PG with nicotine exposed 


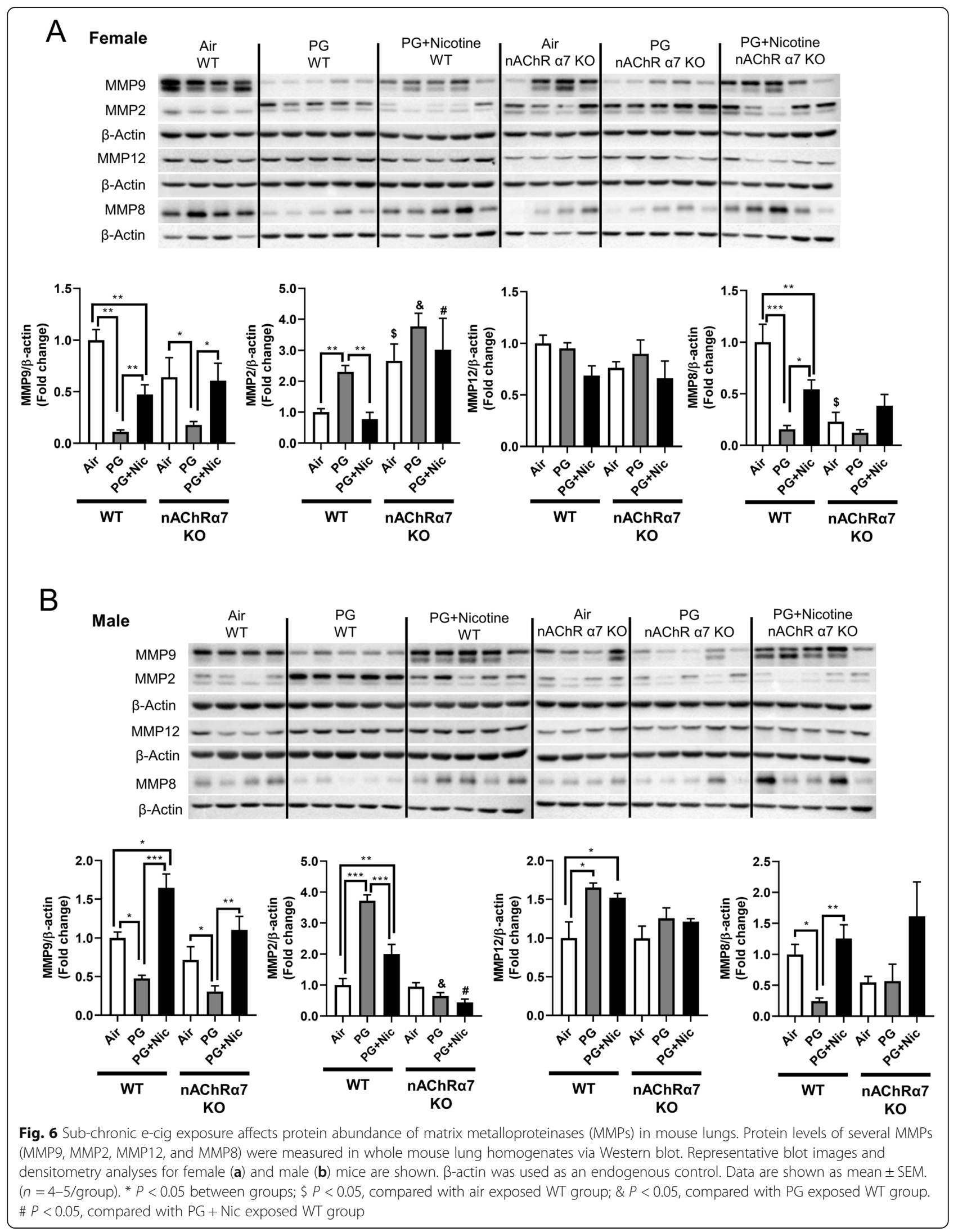




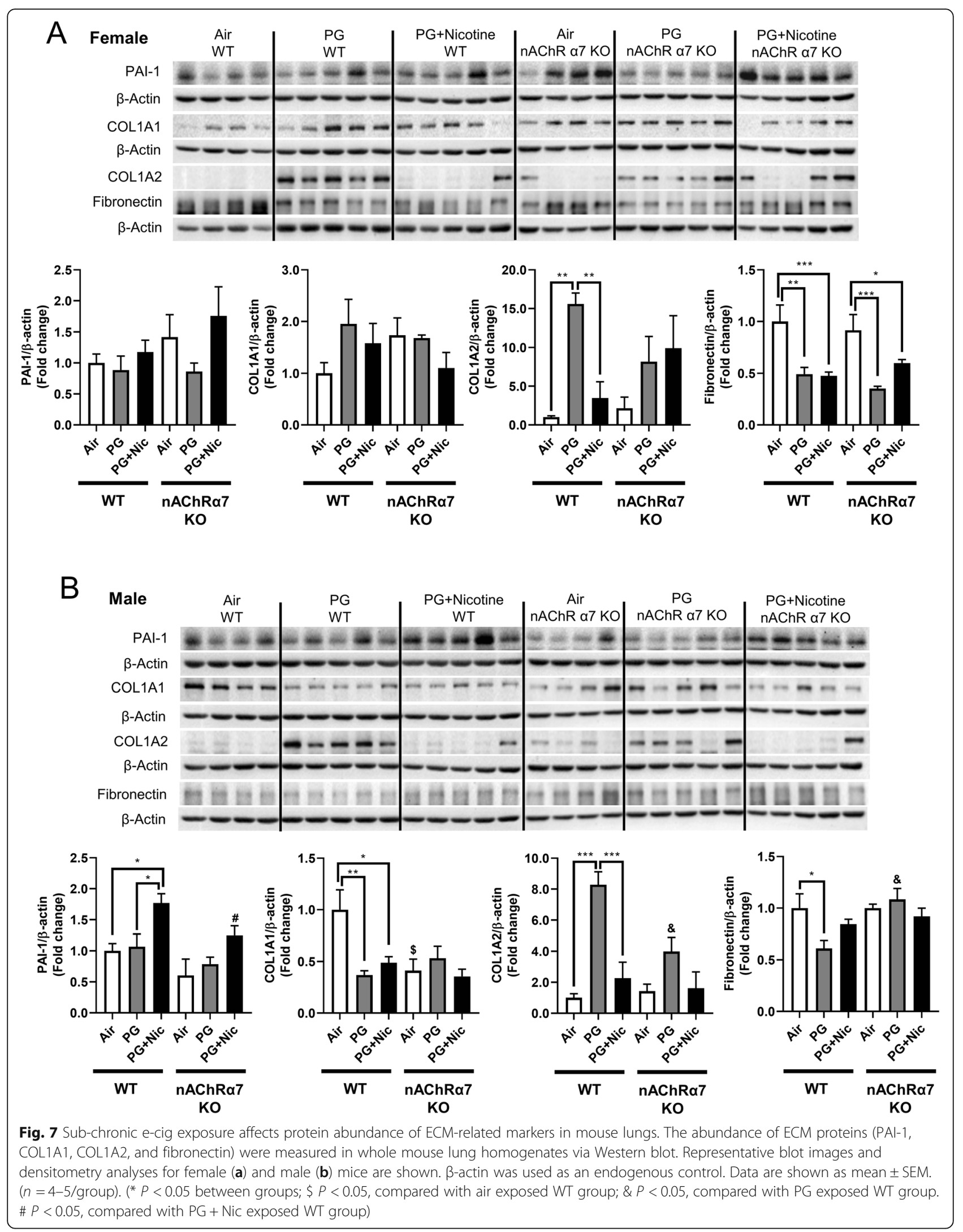


WT mice, while LDLR transcript levels remain unchanged in both PG with and without nicotine exposed nAChR $\alpha 7$ $\mathrm{KO}$ groups. These findings suggest that $\mathrm{nAChR} \alpha 7$ may be an important gateway that affects specific inflammatory response/ECM remodeling target genes during subchronic e-cig exposure with nicotine.

To further study the inflammatory responses, we measured the protein abundance of NF-kB (p50/p105) in both female and male mice. The activation of NF- $\mathrm{KB}$ is well documented in different lung injury models [44] including cigarette smoke-induced inflammation, wheras research on e-cig aerosol induced NF- $\mathrm{kB}$ activation remains less explored [45-48]. Although the anti-inflammatory effects (i.e. inhibition of NF- $\mathrm{kB}$ signaling) via activation of nAChRs is well-known and has been studied previously, nicotine has been shown induce inflammation through activation of the NF- $k B$ signaling pathway $[31,49]$. Our findings suggest that e-cig aerosol containing nicotine increased p50 and p105 protein abundance in female mice in a nAChR $\alpha 7$-dependent manner. We believe nicotine is a potent inducer of altered lung inflammation via activated $\mathrm{nAChR} \alpha 7$ compared to the anti-inflammatory effects regulated by $\mathrm{nAChR}$-related signaling. We found lack of $n A C h R \alpha 7$ showing attenuation of inflammatory response following e-cig exposure with nicotine. However, nicotine-free e-cig exposure increased p105 protein levels, which suggests this subunit may act through an alternative pathway that may be independent of nAChR $\alpha 7$ signaling. We for the first time show that lung inflammation caused by e-cig aerosol containing nicotine is nAChR $\alpha 7$ dependent, probably in a sex-specific manner. However, more detailed studies are needed to further illustrate the exact mechanism by which sex-differences in lung inflammatory responses occur following e-cig exposure through cell-type specific nAChR $\alpha$-mediated signaling.

As we recently reported, acute exposure to e-cig aerosol with or without nicotine resulted in dysregulated repair and ECM remodeling [8]. We noticed similar effects in our sub-chronic exposure model as well. E-cig aerosol with or without nicotine alters MMPs and ECM remodeling proteins in a sex-dependent manner, which are nAChR $\alpha 7$ receptor independent. It is known that nicotine exposure causes harmful respiratory effects, such as airway remodeling and airspace enlargement [50, 51], which are key features of emphysema and COPD [5153]. However, dysregulation of MMPs serves not only as a factor for ECM remodeling, but also as a marker of inflammation mediated by dysregulated macrophages. Based on our results, nicotine-free e-cig aerosol induced augmented MMPs dysregulation more so than e-cig aerosol with nicotine. Increased MMP2/MMP12, along with decreased MMP9/MMP8, might suggest a compensatory feedback loop [54]. We observed that ACE2 is increased by e-cig with nicotine exposure, whereas the level is decreased in nAChR $\alpha 7$-deficient mice, suggesting that ACE2 upregulation by nicotine is mediated by nAChR $\alpha 7$. It is thought that ACE2 is upregulated by smoking, and that its expression level is increased in smokers and COPD patients $[55,56]$, as well as serving as the entry gate for the novel coronavirus (SARS-CoV2) [57]. Hence, e-cig with nicotine inhalation would promote SARS-CoV-2 infection, and $\mathrm{nAChR} \alpha 7$ deletion and downregulation of ACE2 may have some ramifications on viral infection.

One of the major substrates of MMPs is ECM related proteins. From our previous study, mice exposed to ecig aerosols for 3 days showed dysregulated repair/ECM remodeling both at the mRNA and protein levels in a sex-dependent manner [8]. The current study shows that sub-chronic e-cig exposure with or without nicotine affects ECM remodeling to a certain extent dependent on nAChR $\alpha 7$ with some sex-specific phenotypes. We have observed increased PAI-1 only in WT male mice exposed to PG with nicotine in a nAChR $\alpha 7$-dependent manner, and PAI-1 is a primary ECM regulator and profibrotic marker [58]. Therefore, increased PAI-1 following inhalation of e-cig aerosol with nicotine indicates that e-cig vapor containing nicotine could increase risk of chronic fibrotic disease, implicating the crucial role of $n A C h R \alpha 7$-related signaling. Some other ECM proteins, such as type 1 collagen and fibronectin, were altered after exposure of e-cig aerosol with or without nicotine. ECM proteins affected by e-cig exposure are associated with dysregulated wound healing and fibrotic disease [59]. The observed increase in COL1A2 following e-cig with PG alone exposure in both male and female mice demonstrates the significant health risk imposed by PG alone, in addition to the risks associated with PG with nicotine. As mentioned above, nicotine might not be the only target that can activate $\mathrm{nAChR} \alpha 7$, and $\mathrm{PG}$ alone via other indirect mechanisms could activate nicotinic receptors, which may be in agreement with our previous studies $[8,19]$. It is well known that collagen and fibronectin are required during the wound healing process and delayed wound healing is observed when epithelial cells were unable to synthesize fibronectin [60]. We found down-regulation of collagen and fibronectin following e-cig exposure, which will make lungs more vulnerable later in life when exposed to other noxious gases and environmental toxicants. Further studies are required to understand the mechanisms underlying how ecig exposures may induce damaging responses, leading to lung disease and injury.

Based on our findings, long-term studies are needed to provide further insights on how $\mathrm{nAChR} \alpha 7$ dependency plays an important cell-type specific role in the lung (epithelial and fibroblast) during e-cig exposure, and its involvement in ACE2 regulation. We know 
that several factors, such as duration of exposure, route of exposure, dose, e-liquid composition, setting used for delivering the e-cig aerosols, concentration of PG mixture and nicotine, as well as mouse strain, background, and sex of mice may equally contribute to the difference and phenotype observed in the measure outcomes. Chronic e-cig exposures are underway that will help us to understand how these signaling mechanisms are altered by e-cig exposure with and without nicotine, and how these changes may contribute to the respiratory toxicity observed in mice, which could translate to clinical relevance in human e-cig users. Ongoing human studies are being carried out to identify potential targets and toxicity biomarkers that may relate to human respiratory health effects of e-cigarettes.

\section{Conclusion}

In conclusion, $\mathrm{nAChR} \alpha 7$ ablation attenuates the inflammation induced by sub-chronic e-cig exposure, which may be partly due to e-cig induced ECM remodeling/dysregulated repair response in the lung. In a sub-chronic e-cig exposure, nAChR $\alpha 7$ plays a novel role in an anti-inflammatory response induced by nicotine. We show a significant difference in terms of altered genes that belong to inflammation, dysregulated repair and ECM remodeling in WT mice compared to nAChR $\alpha 7$ KO mice when exposed to PG with nicotine. The differential inflammatory cell counts and pro-inflammatory cytokines in BALF were comparable to our previous findings. Hence, $n A C h R \alpha 7$ may play a vital role in the inflammatory responses induced by nicotine-containing e-cig aerosols. Our data suggest that ECM remodeling/dysregulated repair caused by e-cig exposure is mediated by nAChR $\alpha 7$, and occurs in a sex-dependent manner. Overall, e-cig aerosol with nicotine causes lung inflammation due to altered dysregulated repair response and ECM remodeling mediated by $\mathrm{nAChR} \alpha 7$. Deletion of $\mathrm{nAChR} \alpha 7$ may possibly protect against lung inflammation and injury by attenuating associated signaling targets for ECM remodeling. Hence, nAChR $\alpha 7$ is considered a valid target for inflammation induced by e-cig aerosol with nicotine in the lung.

\section{Supplementary information}

Supplementary information accompanies this paper at https://doi.org/10. 1186/s12931-020-01396-y.

Additional file 1 Figure $\mathbf{S 1}$. Sub-chronic e-cig with PG + Nic exposure increased cotinine levels in mouse serum. Mice were exposed to e-cig with or without nicotine for 30 days, and blood was collected through submandibular venipuncture following the final exposure. Cotinine levels were measured in serum samples from WT and nAChR a7 KO mice exposed to PG or PG with nicotine by ELISA (Cat\# CO096D, Calbiotech) ( $n=3-10 /$ group). Figure S2. Sub-chronic e-cig exposure decreased exercise capacity in nAChR a7 KO mice. Mice were exposed to e-cig with or without nicotine for 30 days, and treadmill for exercise ability measurements were performed before the day of sacrifice, after the last exposure. The running distance and running time for $\mathrm{nAChR}$ a7 global $\mathrm{KO}$ and $\mathrm{WT}$ mice (A and $B$, respectively) and $n A C h R$ a7 lung epithelial cell-specific floxed/Cre-CC10 KO mice ( $C$ and $D$, respectively) were recorded separately. ( $n=3-6 /$ group), ${ }^{*} P<0.05{ }^{* * *} P<0.001$ between groups). Figure S3. Volcano plots represent the differentially expressed myeloid genes among air, PG with and without nicotine exposed WT and nAChR a7 KO mice. Nanostring mRNA data set obtained from Nanostring Technologies and analyzed using nSolver. (A) Comparisons between Air vs PG, Air vs PG + Nic, and PG vs PG + Nic in WT mice, with $P<0.05$ considered a significant difference. (B) Comparison between WT and nAChR a7 KO mice exposed to air, PG or PG + Nic that will specifically determine the genotype-dependent change in expression of myeloid genes following e-cig exposure. Figure $\mathbf{S 4}$. Sub-chronic e-cig exposure induced proinflammatory mediators in BALF of nAChRa7 lung epithelial cell-specific KO mice. Bio-Plex Pro mouse cytokine 23-plex assay kit (Bio-Rad) was used to determine levels of pro-inflammatory cytokines/chemokines in BALF from nAChRa7 lung epithelial cell-specific KO mice exposed to ecig for 30 days $(2 \mathrm{~h} /$ day). Significant changes were found in pro-

inflammatory cytokines IL-5, MCP-1, KC, Eotaxin, GM-CSF, and G-CSF (A). All the other pro-inflammatory cytokines such as IL-1a, TNFa, MIP-1 $\beta$, IL-2, IL-9, IFNy, RANTES, IL-6, IL-12p70, IL-13, IL-1 $\beta$, Eotaxin, IL-3, IL-4, IL-10, IL12p40, IL-17A, and MIP-1a (B and C) did not show any significant changes between the groups. Data are shown as mean \pm SEM $(n=3-5$ / group; equal number of male and female mice), ( $P<0.05$, compared with air control).

Additional file $\mathbf{2}$ Table S1. Sub-chronic e-cig exposure using PG with or without nicotine altered blood gas but not hematology. Table S2. Sub-chronic e-cig exposure using PG with nicotine increased proinflammatory cytokines in BALF.

Additional file 3 Table S3.

\section{Abbreviations}

E-cig: Electronic cigarette; ECM: Extracellular matrix; nAChRs: Nicotinic Acetylcholine Receptors; WT: Wild-type; nAChRa7 KO: nAChRa7 knockout; nAChRa7 CreCC10: Lung epithelial-cell-specific nAChRa7 KO; PG: Propylene glycol; VG: Vegetable glycerin; BALF: Bronchoalveolar lavage fluids; MMPs: Matrix metalloproteinases; IPF: Idiopathic pulmonary fibrosis; COPD: Chronic obstructive pulmonary disease; CNS: Central nervous system; LPSs: Lipopolysaccharides; Glu: Glucose; Hb: Hemoglobin; Hct: Hematocrit; AO/PI: Acridine orange propidium iodide; CCL9: Chemokine ligand 9; KLF4: Kruppel-like factor 4; DUSP1: Dual Specificity Phosphatase 1; BTLA: B and T Lymphocyte Associated; SMAD7: SMAD Family Member 7; NFKB: Nuclear factor kappa-light-chain-enhancer of activated B cells; PAI1: Plasminogen activator inhibitor-1; COL1A1: Type 1 collagens chain 1; COL1A2: Type 1 collagens chain 2; ACE2: Angiotensin-converting enzyme 2; SARS-CoV2: Severe acute respiratory syndrome coronavirus 2

\section{Acknowledgments}

The authors thank Dr. Ye, Dongxia, for technical help of running ELISA/ Luminex assays.

Human participants, human data and human tissue Not applicable.

\section{Human ethical approval}

Not applicable.

\section{Authors' contributions}

$\mathrm{QW}, \mathrm{IKS}$, IR conceived and designed the experiments. QW, DL, JHL, TM, SRM conducted the experiments. QW, IKS, DL, TM, SRM analyzed the data. QW, IKS, SRM, IR wrote and revised the manuscript. The author(s) read and approved the final manuscript. 


\section{Funding}

This study was supported by the National Institutes of Health $(\mathrm{NIH})$ 1R01HL135613 and U54 CA228110. The funding body has no role in design of the study, data collection, analysis, and interpretation of data and in writing the manuscript.

\section{Availability of data and materials}

All data and materials are described in the manuscript.

\section{Ethics approval and consent to participate}

This study was performed according to the standards from the United States Animal Welfare Act, National Institutes of Health $(\mathrm{NIH})$. All the animal experiments were followed the protocol approved by The Animal Research Committee of the University of Rochester (UCAR).

\section{Consent for publication}

Not applicable.

\section{Competing interests}

The authors have declared that no competing interest.

\section{Author details}

${ }^{1}$ Department of Environmental Medicine, University of Rochester Medical Center, Box 850, 601 Elmwood Avenue, Rochester, NY 14642, USA. 2Department of Clinical and Translational Research, University of Rochester Medical Center, Rochester, NY, USA.

\section{Received: 14 February 2020 Accepted: 14 May 2020}

Published online: 18 June 2020

\section{References}

1. Farsalinos KE, Polosa R. Safety evaluation and risk assessment of electronic cigarettes as tobacco cigarette substitutes: a systematic review. Ther Adv Drug Saf. 2014;5:67-86.

2. Javed F, Kellesarian SV, Sundar IK, Romanos GE, Rahman I. Recent updates on electronic cigarette aerosol and inhaled nicotine effects on periodontal and pulmonary tissues. Oral Dis. 2017;23:1052-7.

3. Kaur G, Muthumalage T, Rahman I. Mechanisms of toxicity and biomarkers of flavoring and flavor enhancing chemicals in emerging tobacco and nontobacco products. Toxicol Lett. 2018;288:143-55.

4. Lawyer GR, Jackson M, Prinz M, Lamb T, Wang Q, Muthumalage T, Rahman I. Classification of flavors in cigarillos and little cigars and their variable cellular and acellular oxidative and cytotoxic responses. PLoS One. 2019;14: e0226066

5. Madison MC, Landers CT, Gu BH, Chang CY, Tung HY, You R, Hong MJ, Baghaei N, Song LZ, Porter P, Putluri N, Salas R, Gilbert BE, Levental I, Campen MJ, Corry DB, and Kheradmand F. Electronic cigarettes disrupt lung lipid homeostasis and innate immunity independent of nicotine. J Clin Invest. 2019;129:4290-304.

6. Goniewicz ML, Kuma T, Gawron M, Knysak J, Kosmider L. Nicotine levels in electronic cigarettes. Nicotine Tobacco Res. 2012;15:158-66.

7. Grana RA, Popova L, Ling PM. A longitudinal analysis of electronic cigarette use and smoking CessationElectronic cigarette use and smoking CessationLetters. JAMA Intern Med. 2014;174:812-3.

8. Wang Q, Ahmad Khan N, Muthumalage T, Lawyer GR, McDonough SR, Chuang T-D, Gong M, Sundar IK, Rehan VK, Rahman I. Dysregulated repair and inflammatory responses by e-cigarette-derived inhaled nicotine and humectant propylene glycol in a sex-dependent manner in mouse lung. FASEB BioAdvances. 2019:1:609-23.

9. Burgstaller G, Oehrle B, Gerckens M, White ES, Schiller HB, Eickelberg O. The instructive extracellular matrix of the lung: basic composition and alterations in chronic lung disease. Eur Respir J. 2017:50.

10. Wight TN, Frevert CW, Debley JS, Reeves SR, Parks WC, Ziegler SF. Interplay of extracellular matrix and leukocytes in lung inflammation. Cell Immunol. 2017;312:1-14

11. Lerner CA, Sundar IK, Yao H, Gerloff J, Ossip DJ, Mclntosh S, Robinson R, Rahman I. Vapors produced by electronic cigarettes and e-juices with flavorings induce toxicity, oxidative stress, and inflammatory response in lung epithelial cells and in mouse lung. PLoS One. 2015;10:e0116732.
12. Wu Q, Jiang D, Minor M, Chu HW. Electronic cigarette liquid increases inflammation and virus infection in primary human airway epithelial cells. PLoS One. 2014;9:e108342.

13. Zia S, Ndoye A, Nguyen VT, Grando SA. Nicotine enhances expression of the alpha 3, alpha 4, alpha 5, and alpha 7 nicotinic receptors modulating calcium metabolism and regulating adhesion and motility of respiratory epithelial cells. Res Commun Mol Pathol Pharmacol. 1997; 97:243-62.

14. Jensen K, Nizamutdinov D, Guerrier M, Afroze S, Dostal D, Glaser S. General mechanisms of nicotine-induced fibrogenesis. FASEB J. 2012;26:4778-87.

15. Dani JA, MJPB D, B. Behavior: Cellular mechanisms of nicotine addiction Pharmacol Biochem Behav. 2001;70:439-46.

16. Benowitz NL. Nicotine addiction. N Engl J Med. 2010;362:2295-303.

17. Mabley J, Gordon S, PJI P. Nicotine exerts an anti-inflammatory effect in a murine model of acute lung injury. Inflammation. 2011:34:231-7.

18. Su X, Matthay MA, ABJTjoi M. Requisite role of the cholinergic a7 nicotinic acetylcholine receptor pathway in suppressing gram-negative sepsisinduced acute lung inflammatory injury. J Immunol. 2010;184:401-10.

19. Avelar AJ, Akers AT, Baumgard ZJ, Cooper SY, Casinelli GP, Henderson BJ. Why flavored vape products may be attractive: Green apple tobacco flavor elicits reward-related behavior, upregulates nAChRs on VTA dopamine neurons, and alters midbrain dopamine and GABA neuron function. Neuropharmacology. 2019:158:107729.

20. Henderson BJ, Wall TR, Henley BM, Kim CH, Nichols WA, Moaddel R, Xiao C, Lester HA. Menthol alone upregulates midbrain nAChRs, alters nAChR subtype stoichiometry, alters dopamine neuron firing frequency, and prevents nicotine reward. J Neurosci. 2016;36:2957-74.

21. Henderson BJ, Wall TR, Henley BM, Kim CH, McKinney S, Lester HA. Menthol enhances nicotine reward-related behavior by potentiating nicotineinduced changes in nAChR function, nAChR upregulation, and DA neuron excitability. Neuropsychopharmacology. 2017;42:2285.

22. Jensen RP, Strongin RM, DH. Solvent chemistry in the electronic cigarette reaction vessel. Sci Rep. 2017;7:42549.

23. Khan NA, Sundar IK, Rahman I. Strain- and sex-dependent pulmonary toxicity of waterpipe smoke in mouse. Physiol Rep. 2018;6:e13579.

24. Yao H, Arunachalam G, Hwang JW, Chung S, Sundar IK, Kinnula VL, Crapo JD, Rahman I. Extracellular superoxide dismutase protects against pulmonary emphysema by attenuating oxidative fragmentation of ECM. Proc Natl Acad Sci U S A. 2010;107:15571-6.

25. Khan NA, Yogeswaran S, Wang Q, Muthumalage T, Sundar IK, Rahman I. Waterpipe smoke and e-cigarette vapor differentially affect circadian molecular clock gene expression in mouse lungs. PLoS One. 2019;14:e021 1645.

26. Behar RZ, Hua M, Talbot P. Puffing topography and nicotine intake of electronic cigarette users. PLoS One. 2015:10:e0117222

27. Tegin G, Mekala HM, Sarai SK, Lippmann S. E-cigarette toxicity? South Med J. 2018:111:35-8.

28. Gerloff J, Sundar IK, Freter R, Sekera ER, Friedman AE, Robinson R, Pagano T, Rahman I. Inflammatory response and barrier dysfunction by different ecigarette flavoring chemicals identified by gas chromatography-mass spectrometry in e-liquids and e-vapors on human lung epithelial cells and fibroblasts. Appl In Vitro Toxicol. 2017;3:28-40.

29. Sussan TE, Gajghate S, Thimmulappa RK, Ma J, Kim JH, Sudini K, Consolini N, Cormier SA, Lomnicki S, Hasan F, et al. Exposure to electronic cigarettes impairs pulmonary anti-bacterial and anti-viral defenses in a mouse model. PLoS One. 2015;10:e0116861.

30. Glynos C, Bibli S-I, Katsaounou P, Pavlidou A, Magkou C, Karavana V, Topouzis S, Kalomenidis I, Zakynthinos S, Papapetropoulos A. Comparison of the effects of e-cigarette vapor with cigarette smoke on lung function and inflammation in mice. Am J Physiol Lung Cell Mol Physiol. 2018;315:L662-72.

31. Patel H, Mclntire J, Ryan S, Dunah A, Loring R. Anti-inflammatory effects of astroglial alpha7 nicotinic acetylcholine receptors are mediated by inhibition of the NF-kappaB pathway and activation of the Nrf2 pathway. J Neuroinflammation. 2017:14:192

32. Uchiyama S, Noguchi M, Sato A, Ishitsuka M, Inaba Y, Kunugita N. Determination of thermal decomposition products generated from $\mathrm{E}$ cigarettes. Chem Res Toxicol. 2020.

33. Scott A, Lugg ST, Aldridge K, Lewis KE, Bowden A, Mahida RY, Grudzinska FS, Dosanjh D, Parekh D, Foronjy R, Sapey E, Naidu B, and Thickett DR. Proinflammatory effects of e-cigarette vapour condensate on human alveolar macrophages. Thorax. 2018;73:1161-9. 
34. Crawford A, Angelosanto JM, Nadwodny KL, Blackburn SD, Wherry EJ. A role for the chemokine RANTES in regulating CD8 T cell responses during chronic viral infection. PLoS Pathog. 2011;7:e1002098.

35. Ross SH, Cantrell DA. Signaling and function of Interleukin-2 in T lymphocytes. Annu Rev Immunol. 2018;36:411-33.

36. Li H, Nourbakhsh B, Cullimore M, Zhang GX, Rostami A. IL-9 is important for T-cell activation and differentiation in autoimmune inflammation of the central nervous system. Eur J Immunol. 2011;41:2197-206.

37. De Cunto G, Lunghi B, Bartalesi B, Cavarra E, Fineschi S, Ulivieri C, Lungarella $G$, Lucattelli M. Severe reduction in number and function of peripheral T cells does not afford protection toward emphysema and bronchial remodeling induced in mice by cigarette smoke. Am J Pathol. 2016;186: 1814-24.

38. Lim HB, Kim SH. Inhallation of e-cigarette cartridge solution aggravates allergen-induced airway inflammation and hyper-responsiveness in mice. Toxicol Res. 2014;30:13-8.

39. Bhat $P$, Leggatt $G$, Waterhouse $N$, Frazer $H$. Interferon-gamma derived from cytotoxic lymphocytes directly enhances their motility and cytotoxicity. Cell Death Dis. 2017;8:e2836.

40. Whitmire JK, Tan JT, Whitton JL. Interferon-gamma acts directly on CD8+ T cells to increase their abundance during virus infection. J Exp Med. 2005; 201:1053-9.

41. Tecalco-Cruz AC, Rios-Lopez DG, Vazquez-Victorio G, Rosales-Alvarez RE, Macias-Silva M. Transcriptional cofactors ski and SnoN are major regulators of the TGF-beta/Smad signaling pathway in health and disease. Signal Transduct Target Ther. 2018;3:15.

42. Yang $H$, Zhan L, Yang T, Wang L, Li C, Zhao J, Lei Z, Li X, Zhang HT. Ski prevents TGF-beta-induced EMT and cell invasion by repressing SMAD-dependent signaling in non-small cell lung cancer. Oncol Rep. 2015;34:87-94.

43. Ricci C, Ruscica M, Camera M, Rossetti L, Macchi C, Colciago A, Zanotti I, Lupo MG, Adorni MP, Cicero AFG, et al. PCSK9 induces a pro-inflammatory response in macrophages. Sci Rep. 2018;8:2267.

44. Wang J, Liu Y-T, Xiao L, Zhu L, Wang Q, Yan T. Anti-inflammatory effects of apigenin in lipopolysaccharide-induced inflammatory in acute lung injury by suppressing COX-2 and NF-kB pathway. Inflammation. 2014;37:2085-90.

45. Zhang C, Qin S, Qin L, Liu L, Sun W, Li X, Li N, Wu R, Wang X. Cigarette smoke extract-induced p120-mediated NF-KB activation in human epithelial cells is dependent on the RhoA/ROCK pathway. Sci Rep. 2016;6:23131.

46. Tartell HE. Are E-Cigarettes a safe alternative to smoking? Using airway cell cultures to assess early indicators of COPD progression. Inquiries J Student Pulse. 2015;7.

47. Hasnis E, Bar-Shai M, Burbea Z, Reznick AZ. Mechanisms underlying cigarette smoke-induced NF-kappaB activation in human lymphocytes: the role of reactive nitrogen species. J Physiol Pharmacol. 2007;58(Suppl 5):275-87.

48. Liu X, Togo S, Al-Mugotir M, Kim H, Fang Q, Kobayashi T, Wang X, Mao L, Bitterman P, Rennard S. NF-kappaB mediates the survival of human bronchial epithelial cells exposed to cigarette smoke extract. Respir Res. 2008;9:66

49. Iho S, Tanaka Y, Takauji R, Kobayashi C, Muramatsu I, Iwasaki H, Nakamura K, Sasaki Y, Nakao K, Takahashi T. Nicotine induces human neutrophils to produce IL-8 through the generation of peroxynitrite and subsequent activation of NF-kappaB. J Leukoc Biol. 2003;74:942-51.

50. Hahn HL, Lang M, Bleicher S, Zwerenz S, Rausch C. Nicotine-induced airway smooth muscle contraction: neural mechanisms involving the airway epithelium. Functional and histologic studies in vitro. Clin Investig. 1992;70: 252-62.

51. Garcia-Arcos I, Geraghty P, Baumlin N, Campos M, Dabo AJ, Jundi B, Cummins N, Eden E, Grosche A, Salathe M, Foronjy R. Chronic electronic cigarette exposure in mice induces features of COPD in a nicotinedependent manner. Thorax. 2016;71:1119-29.

52. McDonough JE, Yuan R, Suzuki M, Seyednejad N, Elliott WM, Sanchez PG, Wright AC, Gefter WB, Litzky L, Coxson HO, et al. Small-airway obstruction and emphysema in chronic obstructive pulmonary disease. N Engl J Med. 2011;365:1567-75.

53. Shapiro SD. Animal models for COPD. Chest. 2000;117:223S-7S.

54. Kato H, Duarte S, Liu D, Busuttil RW, Coito AJ. Matrix Metalloproteinase-2 (MMP-2) gene deletion enhances MMP-9 activity, impairs PARP-1 degradation, and exacerbates hepatic ischemia and reperfusion injury in mice. PLoS One. 2015;10:e0137642.
55. Leung JM, Yang CX, Tam A, Shaipanich T, Hackett TL, Singhera GK, Dorscheid DR, Sin DD. ACE-2 expression in the small airway epithelia of smokers and COPD patients: implications for COVID-19. Eur Respir J. 2020;55(5).

56. Brake SJ, Barnsley K, Lu W, McAlinden KD, Eapen MS, Sohal SS. Smoking Upregulates angiotensin-converting Enzyme-2 receptor: a potential adhesion site for novel coronavirus SARS-CoV-2 (Covid-19). J Clin Med. 20209(3).

57. Hoffmann M, Kleine-Weber H, Schroeder S, Kruger N, Herrler T, Erichsen S, Schiergens TS, Herrler G, Wu NH, Nitsche A, et al. SARS-CoV-2 Cell Entry Depends on ACE2 and TMPRSS2 and Is Blocked by a Clinically Proven Protease Inhibitor. Cell. 2020;181:271-80 e278.

58. Rabieian R, Boshtam M, Zareei M, Kouhpayeh S, Masoudifar A, Mirzaei H. Plasminogen activator inhibitor Type-1 as a regulator of fibrosis. J Cell Biochem. 2018;119:17-27.

59. Xue $M$, Jackson CJ. Extracellular matrix reorganization during wound healing and its impact on abnormal scarring. Adv Wound Care (New Rochelle). 2015:4:119-36.

60. Kicic A, Hallstrand TS, Sutanto EN, Stevens PT, Kobor MS, Taplin C, Pare PD, Beyer RP, Stick SM, Knight DA. Decreased fibronectin production significantly contributes to dysregulated repair of asthmatic epithelium. Am J Respir Crit Care Med. 2010;181:889-98.

\section{Publisher's Note}

Springer Nature remains neutral with regard to jurisdictional claims in published maps and institutional affiliations.
Ready to submit your research? Choose BMC and benefit from:
- fast, convenient online submission
- thorough peer review by experienced researchers in your field
- rapid publication on acceptance
- support for research data, including large and complex data types
- gold Open Access which fosters wider collaboration and increased citations
- maximum visibility for your research: over $100 \mathrm{M}$ website views per year
At BMC, research is always in progress.
Learn more biomedcentral.com/submissions 